\title{
Remediation of chromium(VI) at polypyrrole-coated titanium
}

\author{
Seán T. Earley · Bernadette E. Alcock • \\ John P. Lowry · Carmel B. Breslin
}

Received: 22 July 2008/Accepted: 7 January 2009/Published online: 23 January 2009

(C) Springer Science+Business Media B.V. 2009

\begin{abstract}
The application of conducting polypyrrole (PPy) and polyaniline (PAni) coated substrates in remediation of chromium, $\mathrm{Cr}(\mathrm{VI})$, is an area of considerable interest. Here, we discuss the implementation of PPy-coated titanium as a new material for the reduction of $\mathrm{Cr}(\mathrm{VI})$ to the less toxic trivalent state, $\mathrm{Cr}$ (III). An alkaline-peroxide based etching process was used to ensure the adhesion of the PPy coatings to the underlying titanium. The PPy films showed excellent resistance to acidic $\mathrm{Cr}(\mathrm{VI})$ solutions and remained adherent after continuous exposure to the solutions. In order to optimise the remediation process a number of experimental parameters were investigated, including the thickness of the PPy coating, the reduction potential used in pre-treatment of the PPy and the degree of solution agitation. The durability of the materials on exposure to the $\mathrm{Cr}(\mathrm{VI})$ test solutions made them suitable for repeated remediation experiments. Following several test-runs, the cleanup efficiency of the material was found to decrease slightly, however, increasing the exposure/experiment time resulted in significantly improved cleanup ability.
\end{abstract}

Keywords Electropolymerization ·

Chromium remediation - Pollution control .

Polypyrrole · Titanium

\section{Introduction}

Hexavalent chromium, $\mathrm{Cr}(\mathrm{VI})$, is a well-documented carcinogen, mutagen and redox active species [1-6]. However,

S. T. Earley · B. E. Alcock $(\bowtie)$ - J. P. Lowry · C. B. Breslin Department of Chemistry, National University of Ireland Maynooth, Maynooth, Co. Kildare, Ireland

e-mail: bernadette.alcock@nuim.ie the use of chromium in industrial processes including corrosion inhibition, metal finishing, tanning and pigment production is still prevalent $[2,7]$. Pollution due to $\mathrm{Cr}(\mathrm{VI})$ is a considerable problem due to its extremely hazardous nature and the relative ease with which it may contaminate the environment. Investigated remediation techniques include electrochemical methods [8, 9], the use of ferrous iron [7], photocatalysis utilising UV illumination of titanium [10, 11] or zinc oxides [12] and a number of other interesting methods including the implementation of copper, hydrogen peroxide, hydrogen sulphide and methylated yeast biomass [13-16]. In the past number of years the use of conducting polymerbased materials in $\mathrm{Cr}(\mathrm{VI})$ remediation has arisen as an interesting area of research $[17,18]$. Typically, a substrate is coated with a layer of conducting polymer, which is then used to reduce the toxic $\mathrm{Cr}$ (VI) to $\mathrm{Cr}$ (III), Eq. 1, which can be removed by precipitation of the chromium hydroxide [19]. Unlike ferrous or photocatalytic based methods, the reducing agent, i.e. the conducting polymer coated substrate, can be easily removed from the system and be regenerated for repeated use.

Both polypyrrole (PPy) and polyaniline (PAni) deposited on a variety of substrates, have been investigated with regards to reduction of $\mathrm{Cr}(\mathrm{VI})$. Wei et al. [18] described the use of a PPy-coated platinum mesh in reducing the $\mathrm{Cr}(\mathrm{VI})$ concentration in acidic solutions. The process involved first depositing PPy on the platinum substrate then reducing it in a conducting solution, in this case $0.1 \mathrm{~mol} \mathrm{dm}^{-3} \mathrm{KCl}$. The coated mesh was then placed in the $\mathrm{Cr}(\mathrm{VI})$-containing acid solution where the reduction of $\mathrm{Cr}(\mathrm{VI})$ was monitored using UV-Vis spectroscopy. The PPy-modified platinum showed excellent cleanup efficiency in comparison to the uncoated mesh. Further development of this work, performed by Senthurchelvan et al. [17], involved the investigation of a glassy-carbon substrate modified with 


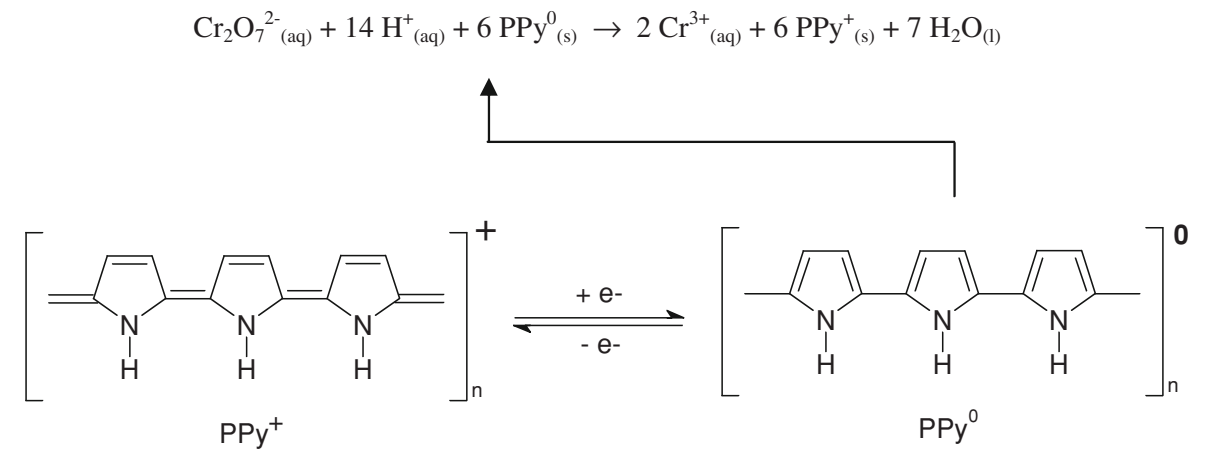

(1)

PPy and provided further insight into the kinetics of the system and the effect of film thickness and $\mathrm{Cr}(\mathrm{VI})$ concentration. The catalytic properties of the film were investigated with cyclic voltammetry as was the stability of the film on exposure to $\mathrm{Cr}(\mathrm{VI})$. Other substrates used in investigations into the $\mathrm{Cr}(\mathrm{VI})$ reducing properties of PPy include carbon black, a highly dispersed form of elemental carbon [20], reticulated vitreous carbon [21] and aluminium [22]. However, titanium possesses several benefits over other previously investigated substrates which include lower cost, its robust nature and resistance to aggressive acidic $\mathrm{Cr}(\mathrm{VI})$ solutions and it is possible to deposit extremely adherent PPy coatings which remain intact after repeated exposure to $\mathrm{Cr}(\mathrm{VI})$ solutions. Additionally, when the PPy coating becomes ineffective through repeated remediation processes it can easily be removed through polishing or sandblasting, allowing the repeated used of the same titanium substrate.

PAni has also been investigated with regards to the remediation of $\mathrm{Cr}(\mathrm{VI})$ [23] and successfully reduces $\mathrm{Cr}(\mathrm{VI})$ to $\mathrm{Cr}$ (III). However, in the case of titanium substrates we found electrochemically deposited PAni coating to be inferior in comparison to PPy with regard to its poor adhesion properties. Here we present the results concerning the remediation of $\mathrm{Cr}(\mathrm{VI})$ with PPy-coated titanium electrodes including the effect of coating thickness, solution agitation, pre-treatment and durability of the coatings. The PPy was deposited potentiostatically using a method previously described in order to obtain extremely adherent coatings on the underlying titanium [24]. The PPy coating was found to be quite resistant to acidified $\mathrm{Cr}(\mathrm{VI})$ solutions used over the course of the investigations and was easily regenerated for repeated use by implementing potentiostatic reduction.

\section{Materials and methods}

Pyrrole (Lancaster) was distilled and stored in the dark at $-20{ }^{\circ} \mathrm{C}$ prior to use. Oxalic acid di-hydrate (99\%, Aldrich) was made to a concentration of $0.2 \mathrm{~mol} \mathrm{dm}^{-3}$ in distilled water. The alkaline-peroxide etch was composed of sodium hydroxide (BDH, technical grade) and hydrogen peroxide (Aldrich, 30\%) diluted in distilled water to the desired concentrations of $0.5 \mathrm{~mol} \mathrm{dm}{ }^{-3} \mathrm{NaOH}$ and $1.0 \mathrm{~mol} \mathrm{dm}^{-3}$ $\mathrm{H}_{2} \mathrm{O}_{2}$. A $0.1 \mathrm{~mol} \mathrm{dm}{ }^{-3}$ aqueous $\mathrm{H}_{2} \mathrm{SO}_{4}$ (BDH, 98\% general purpose reagent) solution was used to make acidified $\mathrm{Cr}$ (VI) solutions with the addition of sodium dichromate2-hydrate $(99.5 \%$, Riedel de Haën). Chemically pure $(99.6+\%)$ titanium wire with a diameter of $1.0 \mathrm{~mm}$ was obtained from Goodfellow Metals Limited.

The titanium wire was prepared by abrading with $\mathrm{p} 1200$ grade SiC paper, cleansing with distilled water and ultrasonic degreasing in acetone for $15 \mathrm{~min}$. Following this, the wire was etched in the alkaline-peroxide solution for 10 min after which it was thoroughly rinsed in distilled water. The PPy coatings were deposited potentiostatically at $0.8 \mathrm{~V}$ (SCE) in a solution of $0.2 \mathrm{~mol} \mathrm{dm}^{-3}$ pyrrole in $0.2 \mathrm{~mol} \mathrm{dm}^{-3}$ aqueous oxalic acid. When the PPy coatings were formed the coated electrode was then potentiostatically reduced in $0.1 \mathrm{~mol} \mathrm{dm}{ }^{-3} \mathrm{H}_{2} \mathrm{SO}_{4}$ for a period of $30 \mathrm{~min}$ at -0.4 or $-0.8 \mathrm{~V}$ (SCE). When the reduction process was completed, the PPy-coated titanium was placed in a UV-Vis quartz cell, containing a known concentration of $\mathrm{Cr}(\mathrm{VI}),\left(\mathrm{Na}_{2} \mathrm{Cr}_{2} \mathrm{O}_{7}\right)$, in $3.0 \mathrm{~cm}^{3}$ of $0.1 \mathrm{~mol} \mathrm{dm}^{-3} \mathrm{H}_{2} \mathrm{SO}_{4}$ solution. All electrochemical procedures were performed using a Solartron 1285 potentiostat. UV-Vis spectroscopy was performed with a Varian Instruments Cary 50 Conc UV-Vis spectrophotometer.

\section{Results and discussion}

\subsection{Preparation of polypyrrole films}

Figure 1 shows a typical current-time transient associated with the potentiostatic deposition of PPy at titanium using an applied potential of $0.8 \mathrm{~V}$ (SCE). A high density of polypyrrole nucleation on the electrode surface is indicated by the rapid rise in current giving the current peak observed 


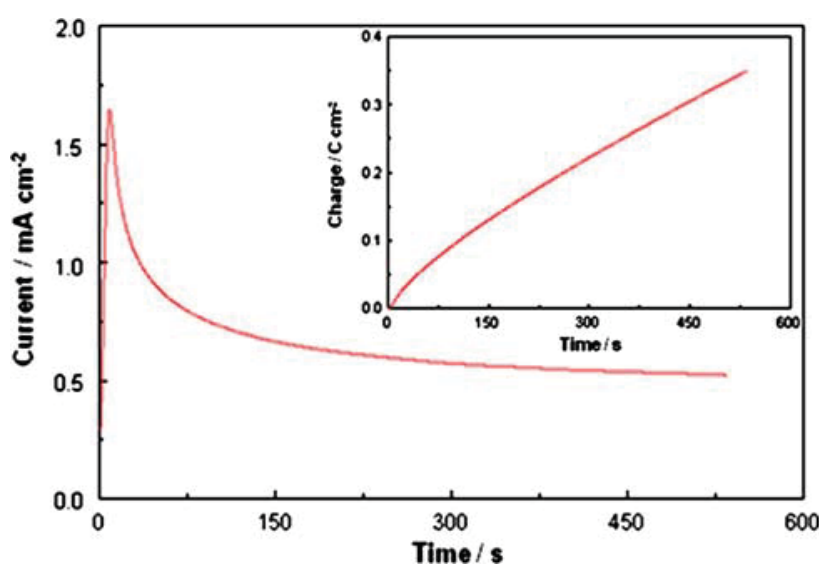

Fig. 1 Typical current-time transient observed on potentiostatic deposition of PPy on titanium. Inset: Charge-time transient obtained from the potentiostatic deposition

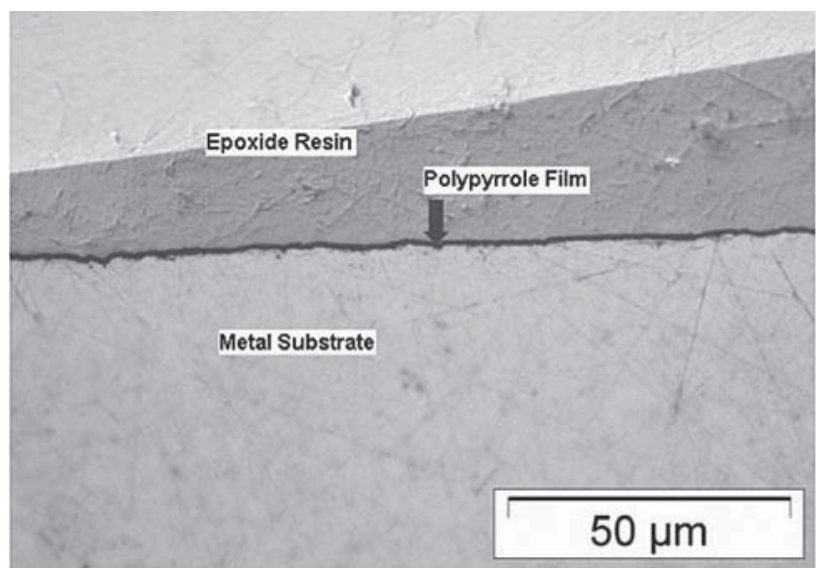

Fig. 2 Example of the cross section of polypyrrole-coated titanium used to estimate the thickness of the coatings

at ca. $30 \mathrm{~s}$. This is followed by unidirectional growth of the coating indicated by a significant drop in current values over the remainder of the electrodeposition. The inset shows the corresponding charge-time plot. In order to determine the thickness of the polypyrrole coatings cross sections of PPy-coated Ti-6Al-4V were obtained. Figure 2 shows an example of the cross section micrographs used to estimate the charge-thickness relationship. Assuming a linear relationship and $100 \%$ current efficiency it is estimated that a charge of $0.35 \mathrm{C} \mathrm{cm}^{-2}$ will deposit PPy to a thickness of $1.0 \mu \mathrm{m}$.

\section{$3.2 \mathrm{Cr}(\mathrm{VI})$ reduction}

Figure 3 shows the typical UV-Vis response of $2.5 \times 10^{-4} \mathrm{~mol} \mathrm{dm}^{-3} \mathrm{Cr}(\mathrm{VI})$ in $0.1 \mathrm{~mol} \mathrm{dm}^{-3} \mathrm{H}_{2} \mathrm{SO}_{4}$ during exposure to a $1.0 \mu \mathrm{m}$ oxalate-doped PPy coating on titanium. Scans of the solution were obtained every $10 \mathrm{~min}$ over a period of $3 \mathrm{~h}$ and show the removal of $\mathrm{Cr}(\mathrm{VI})$ from

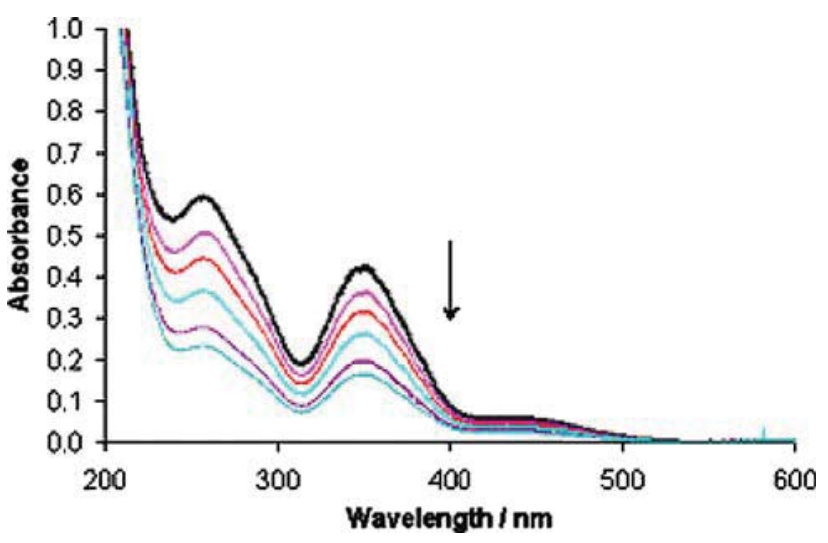

Fig. 3 UV-Vis spectra of $2.5 \times 10^{-4} \mathrm{~mol} \mathrm{dm}^{-3} \mathrm{Cr}(\mathrm{VI})$ in $0.1 \mathrm{~mol} \mathrm{dm}{ }^{-3} \mathrm{H}_{2} \mathrm{SO}_{4}$ during exposure to a $1.0 \mu \mathrm{m}$ oxalate-doped PPy coating on titanium. The traces were recorded at $t=0,10,30$, 60, 120 and $180 \mathrm{~min}$. The solution was agitated with nitrogen bubbling throughout

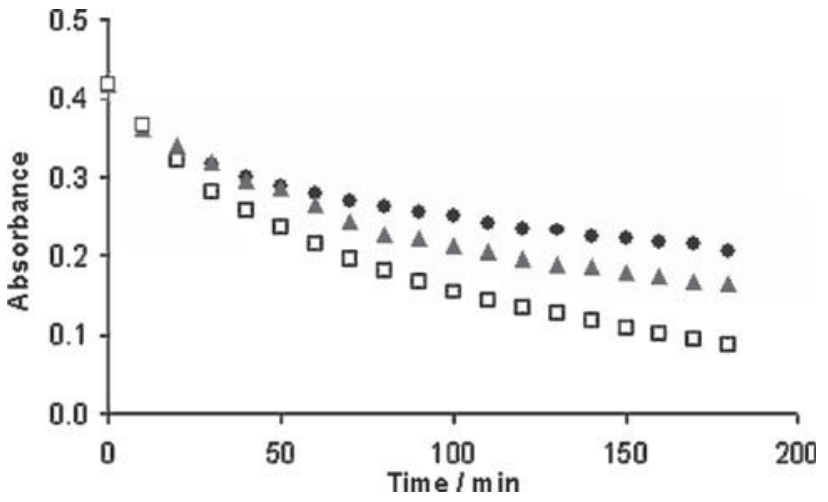

Fig. 4 Absorbance values at $351 \mathrm{~nm}$ shown as a function of the exposure time of PPy-coated titanium to $2.5 \times 10^{-4} \mathrm{~mol} \mathrm{dm}^{-3}$ $\mathrm{Cr}(\mathrm{VI})$ in $0.1 \mathrm{~mol} \mathrm{dm}^{-3} \mathrm{H}_{2} \mathrm{SO}_{4}$. Polymer thickness: $0.5 \mu \mathrm{m}$ $1.0 \mu \mathrm{m} \boldsymbol{\Delta}, 5.0 \mu \mathrm{m} \square$. The solution was agitated with nitrogen bubbling throughout

the solution. This is consistent with the reduction of $\mathrm{Cr}(\mathrm{VI})$ by PPy at other substrates [17-22]. The PPy was grown to a thickness of $0.5,1.0$ and $5.0 \mu \mathrm{m}$ and similar UV-Vis experiments were performed in order to assess the effect of polymer thickness. The thickness of the PPy coatings was estimated based on the charge/thickness relationship determined from cross section measurements of PPy coatings on titanium [25]. Inspection of Fig. 4 shows the increasing ability of the coatings to reduce the $\mathrm{Cr}(\mathrm{VI})$ with increasing thickness, particularly during the later stages of the exposure period. After a $3 \mathrm{~h}$ exposure period the percentage cleanup efficiencies were calculated as 41,50 and $82 \%$ in order of increasing thickness. The increasing efficiency of the thicker coatings is most likely a result of the increased quantity of PPy available for the redox reaction with $\mathrm{Cr}(\mathrm{VI})$. Also, thicker PPy coatings exhibit a rougher morphology and tend to be more porous in nature [26], 
resulting in a higher surface area and improving the capacity of the reaction with $\mathrm{Cr}(\mathrm{VI})$.

The reduction process of chromium at the PPy-coated titanium follows pseudo first-order kinetics with respect to the change in $\mathrm{Cr}(\mathrm{VI})$ concentration. The rate law for the reduction of $\mathrm{Cr}(\mathrm{VI})$ is shown in Eq. 2. Since the concentration of $\mathrm{H}_{2} \mathrm{SO}_{4}$ is significantly higher than that of the $\mathrm{Cr}(\mathrm{VI})$ species, its concentration is expected to vary little during the course of the reaction, likewise the concentration of $\mathrm{PPy}^{0}$ can be taken as a constant. Based on this, Eq. 3 can be derived, where $k^{1}$ represents a pseudo firstorder rate constant. Plotting the logarithm of the $\mathrm{Cr}(\mathrm{VI})$ concentration as a function of time allows the calculation of the rate constants for the reduction of $\mathrm{Cr}(\mathrm{VI})$ by the PPy. Inspection of Table 1 indicates a 2.5-fold increase in the rate of $\mathrm{Cr}(\mathrm{VI})$ reduction with increasing thickness of the PPy from $0.5 \mu \mathrm{m}$ to $5.0 \mu \mathrm{m}$, highlighting the effect of increasing the thickness of the PPy coating.

$\mathrm{R}=k[\mathrm{Cr}(\mathrm{VI})]^{1}\left[\mathrm{PPy}^{0}\right]^{n}\left[\mathrm{H}^{+}\right]^{p}$

$\mathrm{R}=k^{1}[\mathrm{Cr}(\mathrm{VI})]^{1}$

The potential at which the PPy is reduced prior to immersion in the $\mathrm{Cr}(\mathrm{VI})$ solution can also affect the efficiency of the redox process, as this determines to what extent the PPy coating will be reduced. As summarised in Fig. 5, the percentage cleanup efficiencies of PPy reduced at $-0.8 \mathrm{~V}$ (SCE) increased by over $10 \%$ after exposure to

Table 1 First-order rate constants obtained for PPy coatings on exposure to $2.5 \times 10^{-4} \mathrm{~mol} \mathrm{dm}{ }^{-3} \mathrm{Cr}(\mathrm{VI})$ in $0.1 \mathrm{~mol} \mathrm{dm}^{-3} \mathrm{H}_{2} \mathrm{SO}_{4}$

\begin{tabular}{ll}
\hline Coating thickness/ $\mu \mathrm{m}$ & $\mathrm{k} / \mathrm{min}^{-1}$ \\
\hline 0.5 & $(3.3 \pm 0.2) \times 10^{-3}$ \\
1.0 & $(4.9 \pm 0.2) \times 10^{-3}$ \\
5.0 & $(8.3 \pm 0.2) \times 10^{-3}$ \\
\hline
\end{tabular}

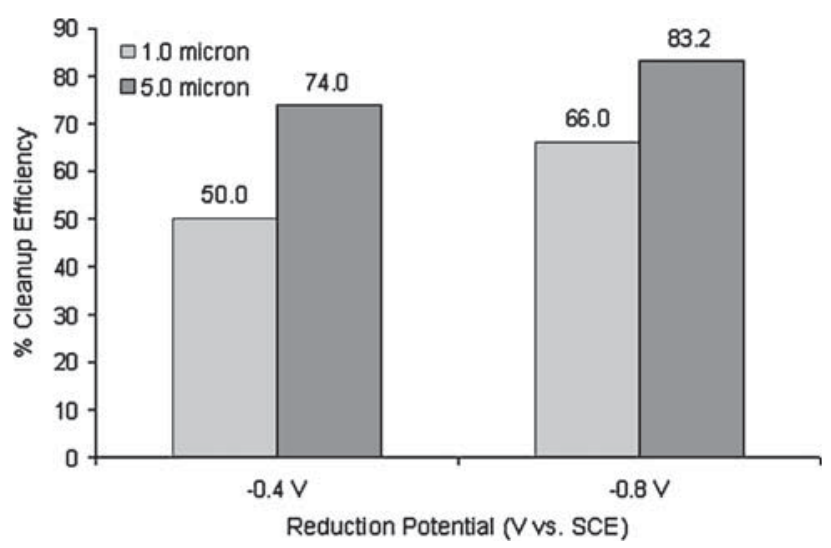

Fig. 5 Percentage cleanup efficiencies, as a function of reduction potential and polymer thickness, after exposure to $2.5 \times 10^{-4}$ mol dm ${ }^{-3} \mathrm{Cr}(\mathrm{VI})$ in $0.1 \mathrm{~mol} \mathrm{dm}^{-3} \mathrm{H}_{2} \mathrm{SO}_{4}$ for a period of $3 \mathrm{~h}$
$2.5 \times 10^{-4} \mathrm{~mol} \mathrm{dm}{ }^{-3} \mathrm{Cr}(\mathrm{VI})$ in $0.1 \mathrm{~mol} \mathrm{dm}^{-3} \mathrm{H}_{2} \mathrm{SO}_{4}$ for $3 \mathrm{~h}$. In the case of PPy, reduction potentials of $-0.9 \mathrm{~V}$ (SCE) have been reported [21] although it should be noted that such negative reduction potentials may significantly damage the PPy and negatively affect its redox properties.

\subsection{Influence of solution agitation}

The degree of solution agitation is another important consideration with regard to maximising the process of $\mathrm{Cr}(\mathrm{VI})$ reduction. Agitation of in-situ UV-Vis experiments was provided by bubbling nitrogen gas through the test solution at a controlled rate over a $3 \mathrm{~h}$ period. On comparison of the percentage cleanup efficiencies without and with agitation, 4.0 and $50.0 \%$, respectively, it is clearly evident that agitation of the solution is necessary to obtain a satisfactory degree of $\mathrm{Cr}(\mathrm{VI})$ reduction. The reduction of $\mathrm{Cr}(\mathrm{VI})$ at the PPy surface is diffusion-controlled and therefore, significant agitation of the test solution will provide the most efficient reduction of the $\mathrm{Cr}(\mathrm{VI})$ in solution. In order to evaluate the effect of vigorous solution agitation, opencircuit potential measurements were used to monitor the oxidation/reduction process occurring at the PPy-coated titanium. The PPy was deposited to an estimated thickness of $1.0 \mu \mathrm{m}$ on titanium wire and reduced at $-0.4 \mathrm{~V}$ (SCE) prior to immersion in the $2.5 \times 10^{-4} \mathrm{~mol} \mathrm{dm}^{-3} \mathrm{Cr}(\mathrm{VI}) /$ $0.1 \mathrm{~mol} \mathrm{dm}^{-3} \mathrm{H}_{2} \mathrm{SO}_{4}$ solution. A UV-Vis cuvette was used to house the electrochemical cell so as to maintain the same surface area/volume ratio used in the UV-Vis in-situ experiments. A silver wire was used as a pseudo $\mathrm{Ag} / \mathrm{AgCl}$ reference. A small magnetic stirrer was used to vigorously stir the solution over the course of the experiment. Stirring was initiated $30 \mathrm{~min}$ after commencing the experiment so as to illustrate the impact of agitation on the rate of $\mathrm{Cr}(\mathrm{VI})$ reduction/PPy oxidation. Figure 6 shows the open-circuit potential values obtained for this experiment. The arrow

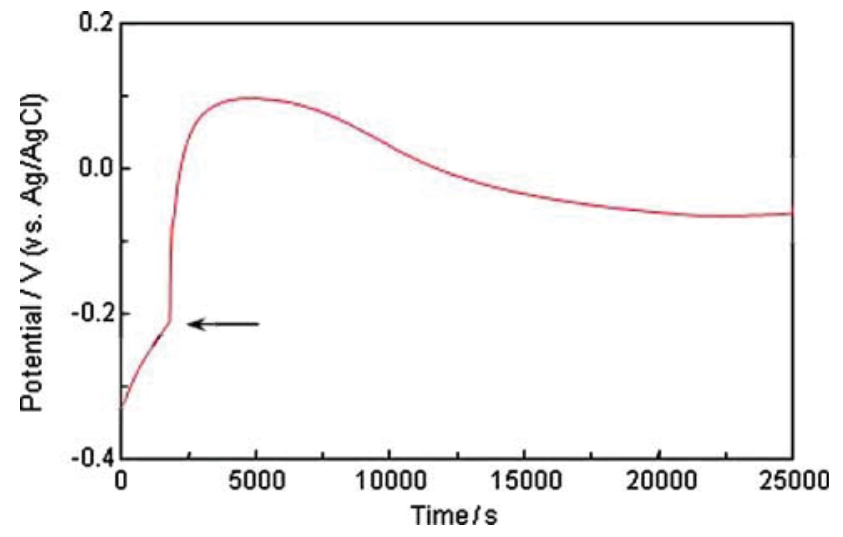

Fig. 6 Open-circuit potential of PPy $(1.0 \mu \mathrm{m})$ on titanium in $2.5 \times 10^{-4} \mathrm{~mol} \mathrm{dm}{ }^{-3} \mathrm{Cr}$ (VI) in $0.1 \mathrm{~mol} \mathrm{dm}^{-3} \mathrm{H}_{2} \mathrm{SO}_{4}$ with solution agitation provided by vigorous stirring following $30 \mathrm{~min}$. The arrow shows the time at which stirring of the solution was initiated 
shows the time at which stirring of the solution was initiated, indicating a significant increase in the rate at which the PPy is oxidised. The maximum potential value was achieved at $c a .83 \mathrm{~min}$, after which the open-circuit potential begins to steadily drop. This indicates the point at which the oxidation of the PPy as a result of the reduction of $\mathrm{Cr}$ (VI) has ceased, and thus the point in time at which all of the $\mathrm{Cr}(\mathrm{VI})$ has been consumed by the redox reaction with PPy. Following the experiment the solution was analysed with UV-Vis spectroscopy and there was no $\mathrm{Cr}(\mathrm{VI})$ remaining whatsoever. This indicates that $100 \%$ cleanup efficiency was obtained after $83 \mathrm{~min}$ of immersion with vigorous agitation of the solution.

\subsection{Durability and re-usability of PPy film}

The durability of the PPy-coated titanium in $\mathrm{Cr}(\mathrm{VI})$ remediation applications is an important consideration. $\mathrm{Cr}(\mathrm{VI})$ is quite a strong oxidising agent and in combination with acidic environments can be potentially damaging to both the PPy and underlying titanium. Open-circuit potential analysis was used to evaluate the resistance of PPy-coated titanium electrodes to corrosion in acidic $\mathrm{Cr}(\mathrm{VI})$ solutions. Open-circuit potential analysis was performed in $0.1 \mathrm{~mol} \mathrm{dm}^{-3} \mathrm{H}_{2} \mathrm{SO}_{4}$ containing $2.5 \times 10^{-4}$ or $1.0 \times 10^{-3} \mathrm{~mol} \mathrm{dm}^{-3} \mathrm{Cr}(\mathrm{VI})$. This analysis is useful in determining the potentials adopted by the PPy/titanium electrode on exposure to $\mathrm{Cr}(\mathrm{VI})$-containing solutions. The PPy-coated titanium was prepared from $0.2 \mathrm{~mol} \mathrm{dm}^{-3}$ oxalic acid electrolyte and grown to an estimated thickness of $1.0 \mu \mathrm{m}$ and then reduced at $-0.4 \mathrm{~V}$ (SCE) in $0.1 \mathrm{~mol} \mathrm{dm}^{-3} \mathrm{H}_{2} \mathrm{SO}_{4}$ before placing in the $\mathrm{Cr}(\mathrm{VI})$ containing solution. Figure 7 compares the open-circuit potential values obtained for PPy-coated titanium wire over a period of $16 \mathrm{~h}$ on exposure to $2.5 \times 10^{-4}$ and $1.0 \times 10^{-3} \mathrm{~mol} \mathrm{dm}^{-3} \mathrm{Cr}(\mathrm{VI})$ in $0.1 \mathrm{~mol} \mathrm{dm}^{-3} \mathrm{H}_{2} \mathrm{SO}_{4}$. The initial open-circuit values indicate that the PPy coatings, which are in a reduced state, are readily oxidised by the $\mathrm{Cr}(\mathrm{VI})$ in the solution. When stirring was initiated at 30 min a rapid increase in the rate of oxidation of the polymer was observed. A maximum potential was obtained at ca. $83 \mathrm{~min}$ in the case of $2.5 \times 10^{-4} \mathrm{~mol} \mathrm{dm}{ }^{-3} \mathrm{Cr}(\mathrm{VI})$ and at ca. $60 \mathrm{~min}$ in the case of the $1.0 \times 10^{-3} \mathrm{~mol} \mathrm{dm}^{-3}$ $\mathrm{Cr}(\mathrm{VI})$ solution. This indicates the time required to consume all of the $\mathrm{Cr}(\mathrm{VI})$ present in the solution by the redox reaction with the PPy. Following these maximum potentials the open-circuit potential was gradually reduced, reaching steady-state values approximately $360 \mathrm{~min}$ after initiating the experiment. The increased rate of oxidation on increasing the $\mathrm{Cr}(\mathrm{VI})$ concentration is quite evident during the first $30 \mathrm{~min}$ of the experiments. Subsequent $\mathrm{UV}-\mathrm{Vis}$ analysis of the solution revealed complete reduction of the $\mathrm{Cr}(\mathrm{VI})$ species. The maximum potentials

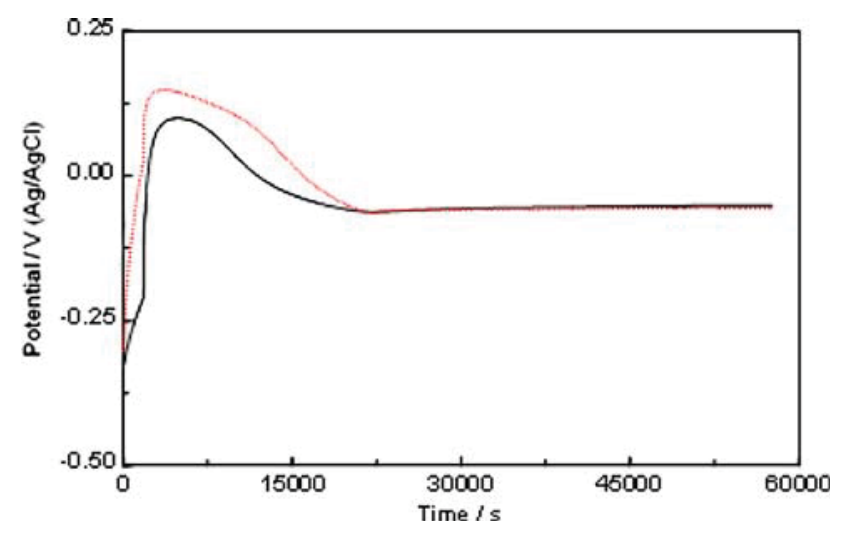

Fig. 7 Open-circuit potentials of PPy-coated titanium $(1.0 \mu \mathrm{m})$ in $2.5 \times 10^{-4}$ - and $1.0 \times 10^{-3} \mathrm{~mol} \mathrm{dm}{ }^{-3}--\mathrm{Cr}(\mathrm{VI})$ in $0.1 \mathrm{~mol} \mathrm{dm}^{-3}$ $\mathrm{H}_{2} \mathrm{SO}_{4}$. Vigorous stirring initiated at $t=30 \mathrm{~s}$

achieved during the course of the $\mathrm{Cr}(\mathrm{VI})$ reduction experiments were 0.098 and $0.148 \mathrm{~V}$ (pseudo $\mathrm{Ag} / \mathrm{AgCl}$ ) for $2.5 \times 10^{-4}$ and $1.0 \times 10^{-3} \mathrm{~mol} \mathrm{dm}^{-3} \mathrm{Cr}(\mathrm{VI})$, respectively. Following the open-circuit potential experiment the PPy coatings remained adherent to the titanium and showed no visible signs of physical damage, indicating the resilience of the coating and underlying titanium in quite aggressive conditions.

An important aspect in the use of conducting polymers in the remediation of $\mathrm{Cr}(\mathrm{VI})$ is their re-usability, i.e. following reduction of $\mathrm{Cr}(\mathrm{VI})$ with the conducting polymer is it possible to regenerate the polymer by electrochemically reducing it? Figure 8 a, b summarise the percentage cleanup efficiencies of PPy-coated titanium with an exposure time of $2 \mathrm{~h}$, having been recycled three times following the initial reduction experiment under gentle or vigorous stirring. The PPy was grown to a thickness of $1.0 \mu \mathrm{m}$ and reduced at $-0.4 \mathrm{~V}$ (SCE) in $0.1 \mathrm{~mol} \mathrm{dm}^{-3}$ $\mathrm{H}_{2} \mathrm{SO}_{4}$ prior to exposure to the acidic $\mathrm{Cr}(\mathrm{VI})$ solution for a period of $2 \mathrm{~h}$. After each experiment the PPy/titanium electrode was removed from the solution, rinsed in distilled water and reduced again for $30 \mathrm{~min}$ before placing in fresh $2.5 \times 10^{-4} \mathrm{~mol} \mathrm{dm}^{-3} \mathrm{Cr}(\mathrm{VI})$ solution. In Fig. $8 \mathrm{a}$ the reduction of the $\mathrm{Cr}(\mathrm{VI})$ was monitored using $\mathrm{UV}-\mathrm{V}$ is spectroscopy as before. Bubbling nitrogen gas was used to agitate the $\mathrm{Cr}(\mathrm{VI})$ test solution throughout the exposure period. Figure $8 \mathrm{~b}$ shows the percentage cleanup efficiencies obtained with vigorous stirring of the $\mathrm{Cr}(\mathrm{VI})$ solution. In this case, the progression of the chromium reduction was monitored with open-circuit potential analysis throughout and the $\mathrm{Cr}(\mathrm{VI})$ concentration was measured following the $2 \mathrm{~h}$ exposure period in order to calculate the percentage cleanup efficiency. Experiments 1-3 involved exposure periods of $2 \mathrm{~h}$ whereas Experiment 4 involved an extended exposure period of $16 \mathrm{~h}$, all performed with the same PPycoated titanium specimen. There was little difference in the 

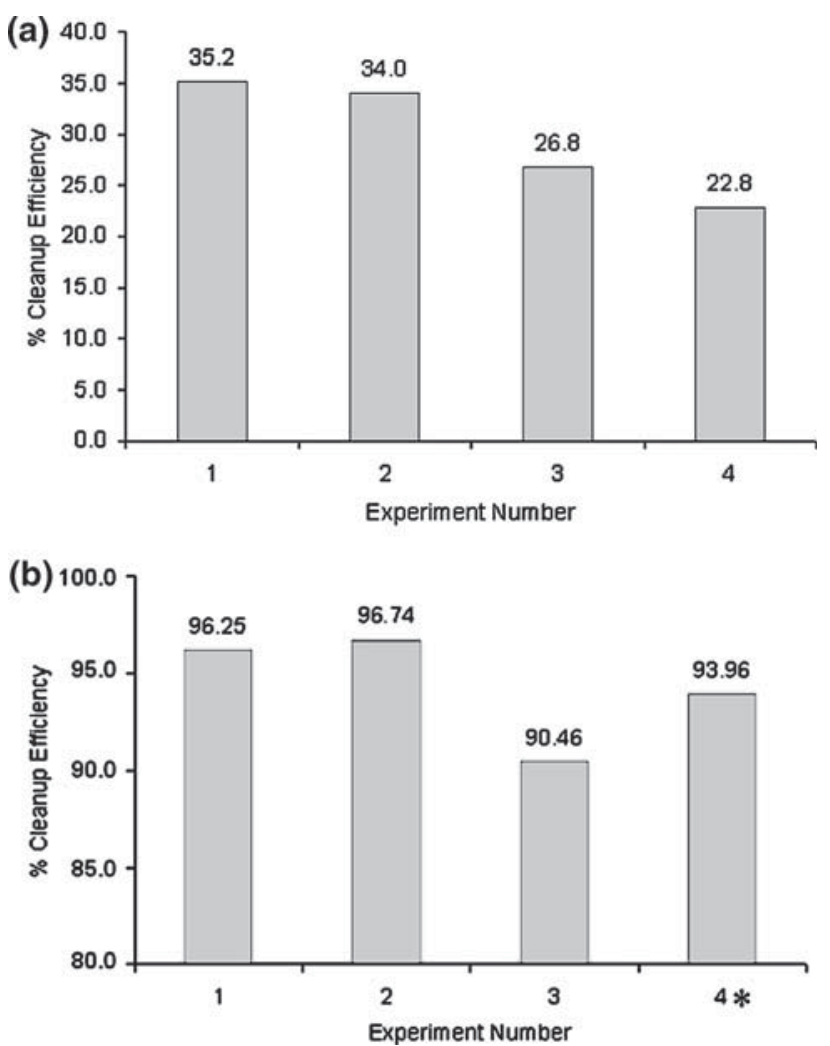

Fig. 8 Percentage cleanup efficiencies in $2.5 \times 10^{-4} \mathrm{~mol} \mathrm{dm}^{-3}$ $\mathrm{Cr}(\mathrm{VI})$ in $0.1 \mathrm{~mol} \mathrm{dm}^{-3} \mathrm{H}_{2} \mathrm{SO}_{4}$ with exposure of the same oxalatedoped PPy/titanium electrode $(1.0 \mu \mathrm{m})$ for each experiment. In (a) the exposure time in each case was $2 \mathrm{~h}$ under gentle agitation and in (b) the exposure time in each case was $2 \mathrm{~h}$ except for $*$ where a time of $16 \mathrm{~h}$ was used, under vigorous stirring

cleanup efficiency in Experiments 1 and 2. However, a decrease of $c a .6 \%$ in the efficiency occurred with Experiment 3. Prior to performing Experiment 3, the specimen had already been exposed to the $2.5 \times 10^{-4} \mathrm{~mol} \mathrm{dm}^{-3}$ $\mathrm{Cr}(\mathrm{VI})$ solution for a period of $4 \mathrm{~h}$ with the two previous experiments. Experiment 4 highlights the significance of exposure time with regard to the reduction of $\mathrm{Cr}(\mathrm{VI})$. Although the rate of reduction of $\mathrm{Cr}(\mathrm{VI})$ had been decreased somewhat as a result of exposure of the PPy to the solution, an increase in the exposure time was effective in providing an increase in the quantity of $\mathrm{Cr}(\mathrm{VI})$ that was reduced. These results obtained with stirring of the solution again highlight the importance of adequate agitation of the $\mathrm{Cr}(\mathrm{VI})$-containing solution with an almost 3-fold increase in the amount of $\mathrm{Cr}(\mathrm{VI})$ reduced when the solution is under vigorous stirring compared to gentle agitation.

In tandem with the re-usability experiment, cyclic voltammetry was used to characterise the PPy coating following each exposure period in the $\mathrm{Cr}(\mathrm{VI})$ solution. The cyclic voltammetry was performed in $0.2 \mathrm{~mol} \mathrm{dm}^{-3}$ oxalic acid solution in each case. Figure 9 shows the cyclic voltammograms obtained on cycling the PPy-coated titanium

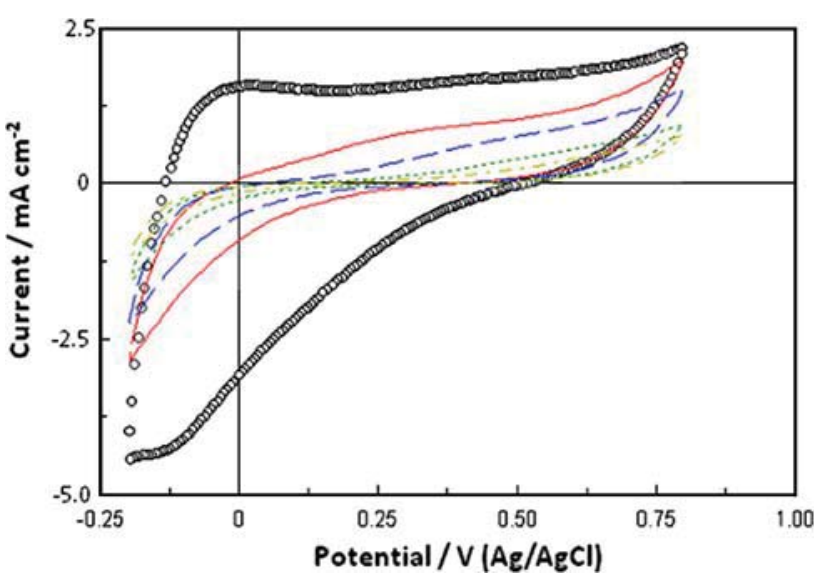

Fig. 9 Cyclic voltammograms recorded for PPy-coated titanium $(1.0 \mu \mathrm{m})$ in $0.2 \mathrm{~mol} \mathrm{dm}^{-3}$ oxalic acid after exposure to $2.5 \times 10^{-4} \mathrm{~mol} \mathrm{dm}^{-3} \mathrm{Cr}(\mathrm{VI})$ in $0.1 \mathrm{~mol} \mathrm{dm}^{-3} \mathrm{H}_{2} \mathrm{SO}_{4}$. Freshly prepared PPy $\bigcirc \bigcirc$, Experiment 1 -, Experiment $2--$, Experiment 3 - - - Experiment $4--(0,2,4,6$ and $22 \mathrm{~h}$ of exposure time)

between -0.2 and $0.8 \mathrm{~V}$ (Pseudo $\mathrm{Ag} / \mathrm{AgCl}$ ) at a scan rate of $50 \mathrm{mV} \mathrm{s}^{-1}$. For comparison purposes, a voltammogram was also obtained for freshly prepared PPy on titanium. On inspection of Figure 9 it is clear that a reduction in the current values occurs in tandem with the length of the exposure period. The oxidising nature of the $\mathrm{Cr}(\mathrm{VI})$ solution contributes to the degradation of the PPy thus, continued exposure can reduce its conducting properties and lead to the reduced current values observed. Although the current values were reduced considerably, the PPy still performed reasonably well obtaining a percentage cleanup efficiency of $93.9 \%$ having been exposed to $2.5 \times 10^{-4} \mathrm{~mol} \mathrm{dm}^{-3} \mathrm{Cr}$ (VI) in $0.1 \mathrm{~mol} \mathrm{dm}^{-3} \mathrm{H}_{2} \mathrm{SO}_{4}$ on three previous occasions for a period of $2 \mathrm{~h}$. Following this series of experiments, the PPy coating was inspected for any signs of physical damage or reduction in its adhesion to the underlying titanium. The coating was found to remain intact and extremely adherent to the underlying titanium.

\section{Conclusions}

Titanium substrates provide a reasonably inexpensive and resilient substrate for the implementation of PPy coatings in the remediation of $\mathrm{Cr}(\mathrm{VI})$ pollution. We found the coated electrodes to be resistant to the acidic $\mathrm{Cr}(\mathrm{VI})$ solutions at open-circuit conditions and also suitable for regeneration, allowing a number of $\mathrm{Cr}(\mathrm{VI})$ reduction experiments from a single test specimen. Results indicate that the ideal parameters for maximising remediation of $\mathrm{Cr}(\mathrm{VI})$ are a combination of thicker PPy coatings, low pretreatment potential (i.e. $-0.8 \mathrm{~V}$ ) and vigorous solution agitation. Additionally, there is the possibility of forming the PPy coatings on titanium substrates with a rough 
surface morphology so as to increase the working surface area and improve the efficiency of the $\mathrm{Cr}(\mathrm{VI})$ reduction process at the PPy surface.

Acknowledgements The authors gratefully acknowledge the support of this work by the Health Research Board and the Environmental Protection Agency, Ireland.

\section{References}

1. Bagchi D, Stohs SJ, Downs BW, Bagchi M, Preuss HG (2002) Toxicology 180:5

2. Cervantes C, Campos-Garcia J, Devars S, Gutierrez-Corona F, Loza-Tavera H, Torres-Guzman JC, Moreno-Sanchez R (2001) FEMS Microbiol Rev 25:335

3. Katz SA, Salem H (1993) J Appl Toxicol 13:217

4. Krumschnabel G, Nawaz M (2004) Aquat Toxicol 70:159

5. Stohs SJ, Bagchi D (1995) Free Radic Biol Med 18:321

6. Vasant C, Balamurugan K, Rajaram R, Ramasami T (2001) Biochem Biophys Res Commun 285:1354

7. Sedlak DL, Chan PG (1997) Geochim Cosmochim Acta 61:2185

8. Abda M, Gavra Z, Oren Y (1991) J Appl Electrochem 21:734

9. Rajeshwar K, Ibanez JG, Swain GM (1994) J Appl Electrochem 24:1077

10. Ku Y, Jung I-L (2001) Water Res 35:135
11. Munoz J, Domenech X (1990) J Appl Electrochem 20:518

12. Domenech J, Munoz J (1987) Electrochim Acta 32:1383

13. Goeringer S, de Tacconi NR, Chenthamarakshan CR, Rajeshwar K (2000) J Appl Electrochem 30:891

14. Kim C, Zhou QH, Deng BL, Thornton EC, Xu HF (2001) Environ Sci Technol 35:2219

15. Pettine M, Campanella L, Millero FJ (2002) Environ Sci Technol 36:901

16. Seki H, Suzuki A, Maruyama H (2005) J Colloid Interf Sci 281:261

17. Senthurchelvan R, Wang Y, Basak S, Rajeshwar K (1996) J Electrochem Soc 143:44

18. Wei C, German S, Basak S, Rajeshwar K (1993) J Electrochem Soc 140:L60

19. Agrawal A, Kumar V, Pandey BD (2006) Miner Process Extr Met Rev 27:99

20. Wampler WA, Basak S, Rajeshwar K (1996) Carbon 34:747

21. Rodriguez FJ, Gutierrez S, Ibanez JG, Bravo JL, Batina N (2000) Environ Sci Technol 34:2018

22. Conroy KG, Breslin CB (2004) J Appl Electrochem 34:191

23. Ruotolo LAM, Gubulin JC (2003) J Appl Electrochem 33:1217

24. Earley ST, Dowling DP, Lowry JP, Breslin CB (2005) Synth Met 148:111

25. Earley ST (2005) Polypyrrole as a potential bioactive coating for metallic implant materials: characterisation and biocompatibility testing. Ph.D Thesis

26. Silk T, Hing Q, Tamm J, Compton RG (1998) Synth Met 93:59 